Fakultät III

Wirtschaftswissenschaften, Wirtschaftsinformatik und Wirtschaftsrecht

Volkswirtschaftliche Diskussionsbeiträge

Discussion Papers in Economics

No. $159-13$

February 2013

Carsten Hefeker · Michael Neugart

Policy Deviations, Uncertainty, and the European Court of Justice 
Universität Siegen

Fakultät III

Wirtschaftswissenschaften, Wirtschaftsinformatik und Wirtschaftsrecht

Fachgebiet Volkswirtschaftslehre

Hölderlinstraße 3

D-57068 Siegen

Germany

http://www.wiwi.uni-siegen.de/vwl/

ISSN 1869-0211

Available for free from the University of Siegen website at

http://www.wiwi.uni-siegen.de/vwl/research/diskussionsbeitraege/

Discussion Papers in Economics of the University of Siegen are indexed in RePEc and can be downloaded free of charge from the following website:

http://ideas.repec.org/s/sie/siegen.html 


\title{
Policy Deviations, Uncertainty, and the European Court of Justice*
}

\author{
Carsten Hefeker $^{\dagger}$ and Michael Neugart ${ }^{\ddagger}$
}

February 14, 2013

\begin{abstract}
The implementation of European Union directives into national law is at the discretion of member states. We analyze incentives for member states to deviate from these directives when the European Commission may sue a defecting member state and rulings at the European Court of Justice (ECJ) are uncertain. We find that higher uncertainty about the preferences of the ECJ increases policy deviation, irrespective of whether a case is taken to court or not. If decisions of member states to deviate are interdependent, the incidence of filed cases decreases while for those policies reaching the ECJ deviations increase.
\end{abstract}

JEL-Classification: D72, D78, K41

Keywords: European Union law, directives, compliance, European Court of Justice, court behavior, uncertainty, legal process, European Commission.

\footnotetext{
${ }^{*}$ The authors declare that they have no conflict of interest.

${ }^{\dagger}$ University of Siegen, Department of Economics, Hölderlinstrasse 3, D-57076 Siegen, e-mail: carsten.hefeker@uni-siegen.de

${ }^{\ddagger}$ Technical University of Darmstadt, Department of Law and Economics, D- 64283 Darmstadt, Germany, e-mail: neugart@vwl.tu-darmstadt.de
} 


\section{Introduction}

Directives play an important role in European Union (EU) law. As with regulations and decisions, directives are legally binding instruments but require the transposition into national legal frameworks (see, Article 288 of the Treaty on the Functioning of the European Union (TFEU)). The choice of method and implementation measure is left to the member countries. This discretion has led to non-compliance by member states with respect to the transposition of directives. Some of these cases are settled between the Commission as the guardian of the European treaties, others surprisingly go to the European Court of Justice (ECJ). By the end of year 2010, for instance, there were 2,100 infringement cases. In the same year $12 \%$ of all cases ended up with the ECJ (European Commission, 2011). What are the drivers behind member states' non-compliance, and when do cases end up at the ECJ?

In this paper we show how uncertainty with respect to the preferences of the ECJ, and political and reputational costs for the European Commission and the member countries of losing a case in front of the ECJ, explain policy deviations from the objectives of European Union law as well as the incidence of cases filed with the ECJ.

To this end, we develop a simple model with three players: a member country, the European Commission, and the ECJ. European Union law in the form of a directive is given, and the member country decides on how and to what degree it implements the directive into its national legal framework. Assuming that the actual directive reflects some kind of a policy compromise between the interest of member states and the Commission, individual member states can be expected to deviate from the policy prescribed if possible. Each member state thus faces a trade-off between exact implementation or deviation. Using the discretion of a directive and deviating, the member country may reduce utility losses by moving closer towards national policy bliss points. However, moving too far away from the aim of the directive may trigger an infringement process that leads the European Commission to file the case with the ECJ.

The ECJ may either confirm the member country's policy implementation, in which case the European Commission would not only have to live with a policy not exactly reflecting its understanding of European Union law, but would likely incur reputational costs because it lost in front of the ECJ. The member state would, if confirmed, have successfully shifted actual policy closer to national policy preferences, but undermined the EU integration process. Should the member state lose in front of the ECJ, however, it would have to confront its citizens with the exact implementation of the European Union law. This would probably lead to a political punishment by its citi- 
zens for not being competent enough to handle directives in such a way that outcomes for its citizens are optimized.

To illustrate the process we aim to explain, we sketch two examples from the data base of decisions by the ECJ, drawing on information provided in the written justification of the decisions of the ECJ: ${ }^{1}$

- Judgement of 14.12.1995 - Case C-16/95 The Eighth Council Directive (79/1072/EEC) of December 1979 harmonizes the laws of the member States relating to turnover taxes. According to Article 7(4) the value added tax to taxable persons not established in the territory of the country has to be refunded within a six-month time-limit.

After numerous complaints from traders of other Member States about delays in refunding the value added tax by the Spanish administration, the European Commission requested explanation from the Spanish Permanent Representative's Office. After not having received an official reply, the European Commission decided to initiate an infringement procedure requesting the Spanish Government with another letter to submit its observations. This request was not fulfilled even after an extension of the time-limit. Next, the European Commission delivered a reasoned opinion, requesting Spain to comply with the directive within another two months. Again no reply was received and the European Commission filed the case with the ECJ.

In court, the Spanish Government did not deny the infringement and explained that delays in refunding value added taxes were due to organizational problems and pointed out that Spanish authorities were seeking ways to comply with the directive in the future.

The ECJ ruled on the basis of established case-law that by disregarding the six-month time-limit for refunding the value added tax Spain failed to fulfil its obligation under the Article 7(4) of the directive.

- Judgement of 30.5.2002 - Case C-441/00 The Council Directive 96/48/EC of 23 July 1995 on the interoperability of the trans-European high-speed rail system has, in particular, the objective to improve the linking and operability of the national high-speed train networks and the access to it.

After the period for transposition for that Directive had expired the European Commission sent a reasoned opinion to the UK government inviting it to take measures to fulfil its obligations. In a reply dated

\footnotetext{
${ }^{1}$ See $h t t p: / /$ curia.europa.eu/jcms/jcms/.
} 
April 5th, 2000, the UK government described legislative problems arguing that it would be able implement the Directive by the end of the year. Next, the European Commission brought the case to the ECJ for reasons that the UK had not adopted the measures necessary to implement the Directive.

The ECJ ruled that the UK failed to fulfil its obligation under that directive.

These cases are merely illustrative for a large number of legal conflicts between member states and the European Commission. Particularly, these two examples give insight into the procedure from which a case in front of the ECJ may emerge. In fact, the cases dealt with by the ECJ cover a broad range of areas from any of the EU member countries. ${ }^{2}$

In our view the explanation for having cases brought forward to the ECJ, and the policy choices of the members states is likely to be found in a nonnegligible degree of uncertainty about the the policy positions and behavior of the ECJ. If the Commission and member states were able to adequately predict the decisions of the ECJ, the losing side should be willing to compromise before being taken to court. A lawsuit is thus likely to reflect a considerable degree of uncertainty and disagreement about the eventual outcome of a legal conflict.

There are several possible justifications where this uncertainty about the court's behavior may come from. First, uncertainty stems from the fact that decisions are taken by a group of judges and that interaction of individuals is not fully predictable. With decision bodies composed of judges from different member states and legal traditions, it may be difficult to infer whose interpretation of a case is going to shape the outcome of the group's decision. In addition, the group size may differ from case to case, and it may not be known before to which chamber a case will be allocated (see Kelemen, 2012). Furthermore, a certain turnover among judges (Malecki, 2012) makes it difficult to predict how the composition of the court will look like. Second, our analysis acknowledges that judges are likely to follow their own policy preferences to some extent (see, e.g., George and Epstein, 1992; Posner, 1993; Segal and Spaeth, 1996; Songer and Lindquist, 1996; Shepsle and Bonchek, 1997; Padovano et al., 2003; Voigt, 2011; Malecki, 2012), for example, by fostering European integration as such. Third, judges could also be influenced by interest groups (Posner, 1993). Since these influences are often implicit and mostly non-predictable, the behavior of judges is, again, to some extent uncertain.

\footnotetext{
${ }^{2}$ See, e.g., Court of Justice of the European Union (2012).
} 
Thus, we argue that uncertainty about ECJ behavior - whatever its exact source may be - is prevalent and that this helps, and indeed might be necessary, to explain member states' implementation of directives, and the interaction between member states and the Commission before the ECJ. Non-compliance of EU members states with EU law, and decisions of the European Commission to seek the support of the ECJ, therefore, take place in the shadow of limited predictability of politically influenced judges.

Our analysis shows that member state compliance with EU directives increases as there is less uncertainty about the policy preferences of the ECJ, irrespective of whether a case is actually taken to court by the European Commission or not. Furthermore, we show that the Commission is taking fewer cases to the ECJ as their is more uncertainty about the preferences of the ECJ, given costs that government and Commission have to carry when losing a case.

By extending our framework to the case where the decision to bring individual countries to court also depends on the behavior of other member states, we furthermore show that there is a higher tendency among member states to avoid policies that trigger a case. But if a policy is chosen that leads to an ECJ case, this policy is more deviant than without interdependent decisions of member states.

We proceed by placing our contribution within the existing literature, and then sketch the institutional background of EU law. Readers acquainted with the legal procedure when the Commission brings a case before the ECJ may skip section 3 . In section 4 , we introduce the actors and in section 5 we solve for the equilibrium choices. In section 6 , we model a many-country setup and introduce strategic interaction between the policy choices of member states. The last section concludes.

\section{Related literature}

The implementation of directives into national law has been intensively studied in the literature on European integration. The many contributions made here may be grouped into two broad fields (see, also, König and Luetgert, 2008). On the one hand, there are studies which argue that the transformation of directives into national legal frameworks is mostly driven by capacity constraints in terms of administrative restrictions or legal complexity. This work very often relies on in-depth studies of the implementation of specific directives from various policy fields (see, e.g. Falkner et al., 2005; Treutlein, 2009). On the other hand, there is the claim that the implementation of directives is best explained on the basis of policy preferences of the various 
actors, including the national members states and their strategic choices. Our contribution sits with the second strand of literature, and relates specifically to the work which attributes to the ECJ a major role in the implementation of European policies.

The role of the ECJ in the context of European integration policies has been heavily debated among, broadly speaking, two opposing groups. Based on ideas by Garrett (1992, 1995); Garrett et al. (1998), Carrubba (2005) has put forward an analysis of the ECJ in which the court decides on implementation issues in a way such that costly overrulings by member states are avoided. Here, the ECJ is seen as a forward-looking actor that derives disutility from being overruled by member states and adjusts its decision accordingly. The second position, taking the opposing view, states that national governments are constrained to obey the rulings of the ECJ, see Burley and Mattli (1993) or Mattli and Slaughter (1995) among others. These authors argue that decisions of the ECJ are always transposed into national law which allows the ECJ to follow its own agenda.

But as fierce as the opposing groups stand against each other on theoretical grounds, no commonly accepted result seems to emerge from empirical studies. Carrubba et al. (2008) test their idea of a forward-looking behavior of the ECJ by tracking so-called briefs sent by member state governments to the ECJ. Assuming that these briefs signal member state preferences on the cases pending, a comparison with the actual rulings of the ECJ should be informative on whether the threat of overruling has driven the ECJ decision. While Carrubba et al. (2008) and Carrubba et al. (2012) claim to find evidence in favor of their proposition, the study is heavily criticized in Stone Sweet and Brunell (2012). Besides referring to the inappropriateness of the underlying sample, these authors argue that one cannot infer from the congruence of a brief with the actual decision of the ECJ that this decision arose because of the fear of being overruled. We side with the second view of the role of the ECJ to the extent that we, too, see the ECJ as an important and independent actor which follows its own interest. The importance of its decisions makes it, as we assume in our analysis, impossible for the member states to not implement what has been decided. But the decision taken at the ECJ is related to the preferences of the judges who decide on a particular case.

Another contribution that links members states' policy choices with the legal process of the Commission filing cases with the ECJ is by Steunenberg (2010). Here, it is argued that costs arising along the judicial process, and the European Commission's policy preferences are key explanatory variables. The Commission chooses different enforcement policies, including a submission of a case to the ECJ, or just stays silent if national implementation 
is sufficiently close to its own preferences. What distinguishes us from this work is our focus on the uncertain preferences of the ECJ. Our main contribution is to show how this uncertainty about the policy preferences of the ECJ is at the root of the choices made, starting from the national member states that decide whether and by how much to deviate when implementing a directive, to the choice of the European Commission whether to file a case with the ECJ. Finally, our modeling of the legal dispute along the judicial process under imperfect information builds on Bebchuk (1984) and Cooter and Rubinfeld (1989).

\section{Institutional Background}

According to Article 288 of the TFEU there are three types of binding legislative instruments: regulations, directives, and decisions. The non-binding instruments are recommendations and opinions. A regulation has general application and is binding in its entirety, and most importantly, is directly applicable in all member states without requiring further action by national governments or parliaments. Decisions are legislative rules that are applicable only to a specific (subset of) members states, firms or individuals. Directives are only binding for the member states with respect to the objective that has to be achieved. ${ }^{3}$ How the objective is reached, in which form and with which methods, is in the discretion of the member states. It is a key feature of directives that member states are given the leeway (subject to a specified time frame) to implement the agreed policy according to the national frameworks of legislation. Member states decide whether this requires changes in their national laws or not. ${ }^{4}$

While each member state is responsible for the implementation of the law within its own legal system, the role of the European Commission is to ensure that the European law is correctly applied, see Article 258 of the TFEU. If, from the point of the view of the European Commission, a member state fails to comply, the European Commission has the power to take action. In such a case it follows a non-compliance procedure in which the first phase is a prelitigation stage where the member state is given the opportunity to comply voluntarily. It starts with a letter of formal notice in which the European Commission states its observation, and points out that it may refer the case to the ECJ and open a litigation procedure. If members states do not take appropriate action, the European Commission may eventually refer the case

\footnotetext{
${ }^{3}$ For a more extensive discussion, see, e.g., Prechal (1995).

${ }^{4}$ For comparative studies of how directives are implemented in selected member states, see Steunenberg and Voermans (2006), Treutlein (2009), or Hartlapp and Falkner (2009).
} 
to the ECJ - as illustrated with the examples in the introduction.

In its 28th annual report on the monitoring of the application of the EU law, European Commission (2011) reports that in year 2010 the acquis communautaire consisted of roughly 8,400 regulations, and 2,000 directives. By the end of year 2010, there was a stock of 2,100 infringement cases. The European Commission took $12 \%$ of all cases to the ECJ in year 2010. According to the evidence reported in Carrubba et al. (2008), and evaluated in Stone Sweet and Brunell (2012), in about 90\% of the infringement proceedings brought forward by the European Commission under Art. 258, the ECJ sided with the Commission against the member state. ${ }^{5}$

\section{The Model}

\subsection{General set-up}

In what follows, we think of a common policy $x_{C}$ as being formulated as a directive. ${ }^{6}$ If member states do not agree with the content of this directive, they may decide to deviate from its implementation, in which case the Commission can decide to take the member state to court. ${ }^{7}$ If it decides to do so, the ECJ will either confirm the member state or the Commission.

We consider the following actors: there are $\mathrm{n}$ member states $i=1 \ldots n$, the European Commission, and the ECJ. ${ }^{8}$ Countries set a common policy $x_{C}$ in a one-dimensional policy space. For simplicity, we assume that this policy $x_{C}$ is exogenous for any single member. ${ }^{9}$ The European Commission in turn

\footnotetext{
${ }^{5}$ Data draws in ECJ decisions from January 1987 to the end of 1997 with more than 400 observations on infringement proceedings.

${ }^{6}$ We think of $x_{C}$ as being exogenous. Typically, one would derive such a policy along the lines of one of the various theories on European integration policies, see, e.g., Pollack (2005). However, what drives the results in our set-up is a conflict of policy goals between the actors involved. As long as the common policy features this characteristic, it is of less importance how it has been derived.

${ }^{7}$ Deviation as a defection on European policies is one option that a members state has when it does not want to comply with European legislation. Such behavior seems to be empirically important as revealed by the results of 90 in-depth case studies by (Falkner et al., 2005, pp. 269) who find that $44 \%$ of the transposition measures were flawed even years after the deadline. The other possibility would be to just postpone the correct implementation in order to gain time. Although we do not have such a time dimension in our model, one may interpret non-compliance in our model as a temporarily limited deviation which improves a member state's payoff in a static setting as ours.

${ }^{8}$ Later on we will consider the interaction between member states.

${ }^{9}$ Alternatively, one could assume that common policy is a weighted average $x_{C}=$ $\sum \alpha_{i} x_{i}^{*}$ of the countries' national policy positions $x_{i}^{*}>0$ and their relative bargaining strength $\alpha_{i}$. Nothing would change in our analysis or results.
} 


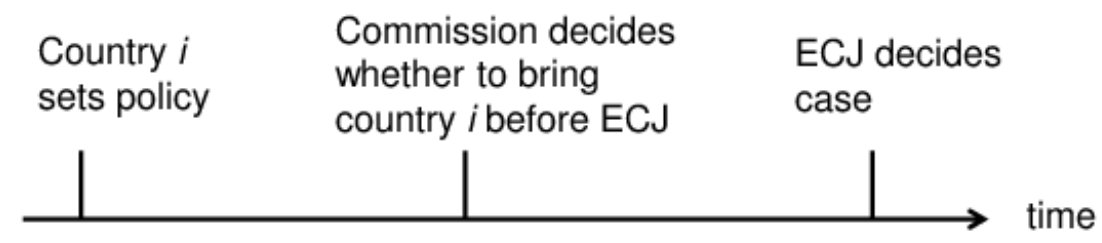

Figure 1: Timing of decisions

is responsible for the correct implementation of policy $x_{C}$ by all member states and may take the case to the ECJ to acquire this objective if country $i$ deviates from $x_{C}$ when implementing the directive. The decision of the ECJ whether the directive was implemented correctly is binding for the European Commission and the country. ${ }^{10}$

The sequence of decisions is illustrated in figure 1: First, country $i$ decides on how to implement a policy $x_{C}$. Then, the European Commission considers whether to accept the way the directive was transposed in national law or to seek a decision of the ECJ. Finally, the ECJ decides and countries implement the ruling.

\subsection{Country $i$}

Each country's preferred policy is denoted by $x_{i}^{*}$. Deviations from a country's most preferred policy cause losses. Whenever actual policy $x_{i}$ deviates from the preferred policy, utility is given as:

$$
U^{i}=-\left|x_{i}-x_{i}^{*}\right|
$$

For notational convenience we reformulate a country's choice variable as a deviation from the directive $x_{C}$ of the European Commission. We set

\footnotetext{
${ }^{10}$ Thus, we abstract form issues of overriding which according to Stone Sweet and Brunell (2012) is empirically not an issue for ECJ rulings.
} 
$\Delta_{i}^{*}=\left|x_{i}^{*}-x_{C}\right|$ and actual policy deviations as $\Delta_{i}=\left|x_{i}-x_{C}\right| .{ }^{11}$ Then, utility written in terms of deviations follows as

$$
U^{i}=-\left(\Delta_{i}^{*}-\Delta_{i}\right)
$$

National losses rise as the difference of the actual deviation $\Delta_{i}$ is smaller than the preferred deviation $\Delta_{i}^{*}$ and thus increases in the difference between both values. It must hold that $\Delta_{i}^{*} \geq \Delta_{i}$ as countries will never deviate more from the directive than is needed to reach their bliss points.

Should the policy choice of a country $i$ be overruled by the ECJ, it has to implement $x_{C}$ implying $\Delta_{i}=0$. Furthermore, we assume that being brought to court and losing implies a loss $\gamma_{G}$ that is proportional to the actual policy deviation $\Delta_{i}$ :

$$
U^{i}=-\Delta_{i}^{*}-\gamma_{G} \Delta_{i}
$$

Our motivation for this assumption is that the political costs for being corrected by the ECJ are higher if the correction is larger as this reflects a larger deviation of EU policy from national preferences. The rejection of the implementation of a directive into national law by the ECJ may be costly to a government as it signals to the voters its lack of competence on how to adapt European policies so that they are in line with the preferences of the citizens of that particular member country. The more distant the European policy is from the stance of its citizens, the more costly such a failure may become for the implementing government.

\subsection{The European Commission}

Based on the explicit role of the European Commission as the guardian of the treaty and the integration process more broadly, we assume its preferences are defined as losses accruing from the deviation of a country $i$ 's actual policy from the directive:

$$
U^{C}=-\Delta_{i} .
$$

In order to avoid those losses, the European Commission may decide to take the member state to the ECJ. If the position of the European Commission is confirmed by the ECJ its losses are zero $\left(\Delta_{i}=0\right)$. If, however, the ECJ confirms the policy of the member state, we assume that losses are given as

\footnotetext{
${ }^{11}$ Alternatively, one could set $x_{C}=0$ and interpret $x_{i}>0$ as the policy deviation. To stress, however, that national policy can deviate in both directions $x_{i} \lessgtr x_{C}$, we use $\Delta_{i}$ instead.
} 


$$
U^{C}=-\Delta_{i}\left(1+\gamma_{C}\right)
$$

with $\gamma_{C}>0$. Using the same type of utility function as for the countries, this implies that the Commission's losses increase with the size of the deviation of a single country's national implementation from the directive. We interpret these losses as the European Commission's failure to fulfill its obligation, being in charge of making sure that member states fulfill their obligation from membership. Should the European Commission file a case with the ECJ and lose, there is hence a price to pay in terms of reputational costs $-\gamma_{C} \Delta_{i}$. The more a country deviates, the more the European Commission loses "its face" if countries get away with an implementation of the directive not in line with $x_{C}$.

There are several ways to justify this assumption. First, the European Commission might just dislike being rejected by the ECJ as this would be an unfavorable judgement on the European Commission and the quality of its legal service. Second, it may fear that such an incidence would invite the same or other countries to deviate from European policies in this or other areas as well. Finally, bringing a lawsuit against a country and being overruled by the ECJ could be interpreted as a failure of the European Commission in its role as a guardian of the treaty, and undermine its future role within the European political architecture.

\subsection{The European Court of Justice}

As underpinned in the introduction, we assume that the judges of the ECJ follow to some degree their own preferences with respect to the interpretation if the chosen policy of a member state is consistent with EU law. Judges, although appointed by governments of member states and charged with implementing the regulations and laws of the EU, may also bring their own policy preferences to a particular decision. However, we do not ask how a particular position within the body is reached but only look at the actual ruling, thus neglecting issues of decision making within the collegiate. Rather, the outcome of this group decision involves uncertainty for the member states and the Commission. The consequence of these individual political leanings of judges may also be reinforced by the small size of chambers, as usually only three to five judges handle a large bulk of the cases at the ECJ. According to Court of Justice of the European Union (2011), 225 of the 279 assigned and pending cases by the end of year 2010 were dealt with by these small chambers as opposed to the Grand Chamber which consists of 13 judges (see, Art. 11c of the Rules of Procedure of the Court of Justice). In particular, in 
those smaller groups individual judges and their personal interests may significantly influence the outcome of lawsuits brought against member states (Malecki, 2012).

To reflect these personal interests and opinions in the decisions of the ECJ, we let $\varepsilon$ be the ECJ's preference for (or against) country $i$ 's government. We assume that $\varepsilon$ can be positive or negative and is distributed uniformly on $\left[-\frac{\mu}{2}, \frac{\mu}{2}\right]$, implying that it is not exactly known by the European Commission and the countries' governments. Obviously, the parameter $\varepsilon$ shifts the bliss point of the ECJ. It is neutral towards the countries and matches the bliss point $x_{C}$ of the European Commission for $\varepsilon=0$.

Figure 2 illustrates for a one dimensional policy space how to think about government's preferred policy and the common policy, which is the preferred position of the European Commission. From the point of view of government and Commission, the court's preferred policy stance is uncertain and may, depending on the size of $\varepsilon$, be closer to that of government or Commission. The court, of course, will side with that position that is closer to its own policy preference, as its utility is decreasing when moving away from its own bliss point.

\section{Policy Choices}

Next we proceed to analyzing the optimal decisions of the players involved. Using backward induction, we first determine the probability that the ECJ sides with the European Commission and forces country $i$ to exactly implement the directive. Then, we look into the decision of the European Commission to file a suit with the ECJ, and finally we determine the policy choice of country $i$. We focus on a non-technical derivation and discussion of the decisions of the actors, and delegate the formal analysis to the Appendix.

\subsection{The Decision of the European Court of Justice}

The ECJ will support the Commission if the utility it obtains with that decision is larger than the utility it receives from tolerating a policy deviation by country $i$. The choice of the ECJ is between confirming what the country has implemented, in which case the court has utility $U_{i}^{J}=-\Delta_{i}$, or to decide in favor of the European Commission, in which case the directive has to be implemented in terms of $x_{C}$ and the ECJ's utility is $U_{C}^{J}=0$.

The ECJ will side with the European Commission if

$$
U_{C}^{J}>U_{i}^{J}+\varepsilon
$$




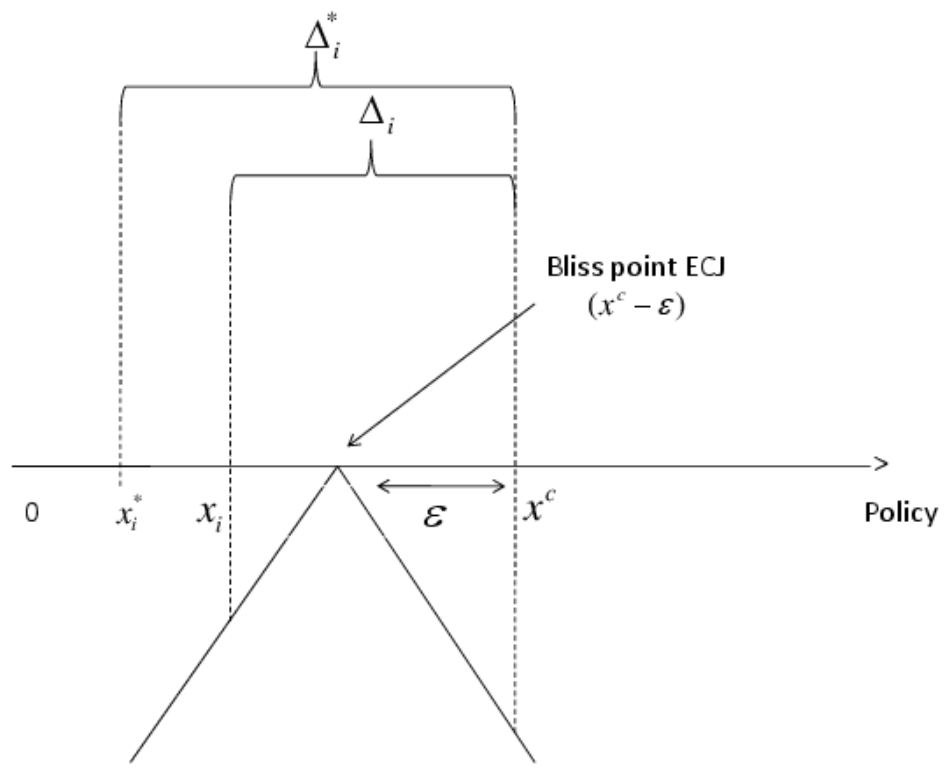

Figure 2: Preferences and policy space 
where $\varepsilon$ measures how much the ECJ leans either towards the European Commission or the member state. Inserting $U_{C}^{J}=0$ and $U_{i}^{J}=-\Delta_{i}$ yields the condition for the ECJ to follow the European Commission's position and ruling in favor of its preferred policy $\Delta_{i}=0$ as

$$
\Delta_{i}>\varepsilon,
$$

i.e. the ECJ will rule against the member state if this member state's implementation of the directive deviates to much relative to the ideal point of the ECJ.

\subsection{The Decision of the European Commission}

Next we consider the European Commission's decision whether to take the member state to court. The European Commission is free to evaluate the implementation of a directive as adequate or not (although it has to treat member states roughly equally, see section 6).

Assume that the European Commission will go to court if the expected payoff is higher than accepting the policy choice of the member country. In case of a trial and a decision of the ECJ supporting the European Commission's point of view, the European Commission would obtain a payoff of zero, and thus the best outcome from its point of view. For the case that the ECJ sides with the country and approves the implementation of the directive, the European Commission faces losses accruing from the deviation of the actual policy choice and from losses in its reputation.

Proposition 1 The European Commission goes to court if country i's policy deviation $\Delta_{i}$ is above a critical value

$$
\Delta_{i}>\bar{\Delta}_{i} \equiv \mu\left(\frac{1}{2}-\frac{1}{1+\gamma_{C}}\right) .
$$

Proof. See Appendix A.

Whenever the policy deviation by country $i$ is above the critical level $\bar{\Delta}_{i}$ the European Commission goes to court. The critical level is increasing in $\mu$, i.e. the uncertainty about the ECJ ruling. Thus, a country's deviation from the bliss point of the European Commission can be larger without the European Commission taking the case to the ECJ if there is higher uncertainty about the court's preferences.

Similar comparative static results arise for the reputational costs of the European Commission. As these rise, the country may deviate to a larger degree without being sued by the European Commission. This is because the 
risk for the European Commission of going of court and losing is accompanied by larger costs. Obviously, if there were no uncertainty about the court's decision $(\mu=0)$ or if the Commission would incur no or only little costs from losing $\left(\gamma_{C}<1\right)$, the Commission would tolerate not the slightest deviation. ${ }^{12}$ Thus, the costs from losing must be high enough for the Commission to accept that states deviate $\left(\gamma_{C}>1\right)$.

One could expect that politically sensitive and widely discussed cases may yield this kind of sufficiently high reputational losses for the European Commission. Thus, more prestigious and visible policy areas may involve lower levels of ECJ activity because the potential costs of losing increase for the European Commission and prompt it to be more cautious about filing cases.

\subsection{Optimal Policy of Country $i$}

Now, we turn to the policy choice of country $i$, given its expectations about the court's behavior and the decision of the European Commission to go to court or not. Member state $i$ decides on how to implement the directive into the national legal framework by comparing the utility levels that accompany its choices. The country may opt for an implementation $\bar{\Delta}_{i}$ which avoids a legal battle in front of the ECJ. Alternatively, it may also choose a policy from which it expects to trigger a filing of the case by the European Commission $\Delta_{i}>\bar{\Delta}_{i}$. The result may be a decision of the ECJ in favor or not in favor of the country's policy choice. Obviously, country i's expectation on the consequences of its policy choice depends on how close its own preferences are to the court's preferences. Thus, we first have to find a policy $\widehat{\Delta}_{i}$ which maximizes the expected utility of the country given that it triggers a filing of the case by the Commission, and then compare this with the payoff from choosing $\bar{\Delta}_{i}$ which would avoid a filing.

Proposition 2 Country i chooses optimal policy

$$
\widehat{\Delta}_{i}=\frac{\mu}{4} \frac{1-\gamma_{G}}{1+\gamma_{G}}
$$

above the critical level $\bar{\Delta}_{i}=\mu\left(\frac{1}{2}-\frac{1}{1+\gamma_{C}}\right)$ if

$$
\frac{1}{16} \frac{\left(1-\gamma_{G}\right)^{2}}{1+\gamma_{G}}>\frac{1}{2}-\frac{1}{1+\gamma_{C}}
$$

\footnotetext{
${ }^{12}$ Given our assumption about the court's preferences $(6), \mu=0$ implies that the court will always side with the Commission's position.
} 
The optimal policy deviation is increasing in uncertainty about the preferences of the ECJ.

Proof. See Appendix B.

No matter whether country $i$ sets $\widehat{\Delta}_{i}$ or $\bar{\Delta}_{i}$ as policy, the country deviates more from $x_{C}$ the larger is uncertainty about the preferences of the ECJ. Thus, as $\mu$ increases, meaning that the location of the bliss point of the ECJ becomes more uncertain, the optimal policy implementations shift closer to the bliss point of the country. Moreover, the condition shows that the country will set a policy that is likely to trigger a case before the ECJ if its reputational costs from losing are sufficiently low relative to those of the Commission. Given that the country chooses a policy that triggers the filing of a case by the European Commission, higher costs of losing shift the policy choice closer to the bliss point of the Commission. Note, that the costs of losing must be low enough for the country's optimal policy to deviate from the directive $\left(\gamma_{G}<1\right)$. Intuitively, this requires that the political or reputational costs from losing a case must not be larger than the costs of implementing a non-desirable policy.

Member states will only accept the risk of being brought to court if the reputational costs they would be incurring when losing are relatively small compared to the reputational costs of the European Commission. ${ }^{13}$ As one would have imagined, for given reputational costs of a country $i$, the European Commission is less likely to file a lawsuit the higher its reputational costs are. Notice that uncertainty about the court's preference, $\mu$, does not influence this decision because it enters the optimal policy for the member state and the critical level of deviation, eq. (8), for the Commission symmetrically and thus cancels out.

\section{$6 \quad$ Interdependent Decisions}

So far, we have analyzed the interaction between the Commission and a single member state. Assuming that the decision to bring member states before court is independent from the behavior of other member states ensures that there is no strategic interaction between member states. However, the incentive to deviate may be a function of the policies other member states pursue. In what follows, we therefore consider the interaction between member states that arises if the European Commission treats all member states equally when deviating from a given policy. It is rather unlikely that the European Commission will bring one member state before court for a given

\footnotetext{
${ }^{13}$ Appendix $\mathrm{C}$ demonstrates, this condition is fulfilled whenever $\gamma_{G}<1<\gamma_{C}$.
} 
deviation but not another one when implementing the same policy as this would imply that the European Commission treats member states differently. Such behavior by the European Commission would most likely expose it to allegations by media and member states of being partial and severely undermine its credibility.

In the next step, we thus analyze the case where the European Commission is committed to treating all member states equally when deciding about bringing them to court. This creates a strategic interaction between member states as the probability of being brought before the ECJ depends on the policy of the other member state in addition to one's own policy.

As a straightforward extension to the assumptions already made, assume that the European Commission's losses are increasing in the sum of deviations of identical member states. That is, the more countries deviate the more the European Commission is perceived as failing to guarantee the implementation of EU policy.

Again, the analysis begins with the behavior of the court. We assume that it will rule against all countries if :

$$
U_{C}^{J}>\frac{1}{n} \sum U_{i}^{J}+\varepsilon
$$

where $U_{C}^{J}=0, U_{i}^{J}=-\Delta_{i}$. As before, we assume that the court may be leaning towards member states to the extent $\varepsilon$. Thus, the court has a preference for following European policy (expressed as $\varepsilon$ ) and rules against member states if the average policy deviation by member states is too high.

In analogue to (8), the European Commission goes to court against all member states if their average policy deviation is above the critical level

$$
\frac{\sum \Delta_{i}}{n}>\bar{\Delta}_{i}=\mu\left(\frac{1}{2}-\frac{1}{1+\gamma_{C}}\right) .
$$

Comparing (12) with (8) reveals the strategic interaction between member states. The higher is the policy deviation of one country, the lower the deviation of other countries must be in order not to trigger a decision by the European Commission to go to court against all. That is, if a single country expects the others not to deviate (or deviate only a bit), it can afford a larger deviation and vice versa. ${ }^{14}$ In such a set-up we get the following results.

\footnotetext{
${ }^{14}$ We assumed identical member states and thus equal weights on the deviations of each member state in the evaluation of the Commission and the ECJ. But assume, for the moment, that we had countries of different size and therefore weights. One implication would be that smaller countries (which have a weaker influence on average deviation) may be tempted to free-ride on larger countries. Thus, it might actually be easier for smaller
} 
Proposition 3 In the n-country case, optimal policy for each country is

$$
\widehat{\Delta}_{i}=\frac{n \mu}{2(n+1)} \frac{1-\gamma_{G}}{1+\gamma_{G}} \text {. }
$$

Countries will set this policy instead of the critical level $\bar{\Delta}_{i}=\mu\left(\frac{1}{2}-\frac{1}{1+\gamma_{C}}\right)$ if

$$
\frac{n}{4(n+1)^{2}} \frac{\left(1-\gamma_{G}\right)^{2}}{1+\gamma_{G}}>\frac{1}{2}-\frac{1}{1+\gamma_{C}} .
$$

Proof. See Appendix D.

Compared to the result without strategic interaction, eq. (9), we conclude that an individual country's policy is more deviant if the European Commission's decision depends on the action of more than one member state. The reason for this is that governments are less disciplined when decisions are interdependent. If the other country deviates less, the European Commission is less likely to take both countries to the ECJ. Thus, member states free ride on each other and since both behave in this way, overall policy deviations increase.

Comparing the incentive to set deliberately a policy deviation above the critical level with the single country case (10) reveals that the condition in the many country case is more binding (since the left hand side is slightly smaller for all $n>1$, whereas the right hand side is unchanged). This means that there is a tendency to rather accept $\bar{\Delta}_{i}$ than being brought to court in the case of several countries. This follows from the fact that deviations are higher in the many country case and thus is the probability of losing in front of the ECJ. The higher risk makes the alternative policy choice $\bar{\Delta}_{i}$ more attractive.

\section{Conclusions}

Member states have considerable leeway in deciding how and to what extent they implement EU directives nationally. We argue that uncertainty is a driving force behind policy deviations of member states and the incidence of cases going to the ECJ, irrespective of whether the European Commission, as the guardian of the treaty, will take member states to court when deeming them in violation of the acquis communautaire.

countries to deviate from EU directives without having to fear that the Commission takes them to court, provided the majority of EU countries implements the directive. It would, therefore, not be clear that larger countries would have more chances to get away with not implementing EU policy. 
Our attempt to explain non-compliance of EU members states with EU law and the incidence of ECJ ruling builds on limited predictability of politically influenced judges, and costs for the European Commission and the member countries of losing a case in front of the ECJ. This un-predictability about the ECJ policy position, we argue, is likely to be grounded in the judges self-interest, and in line with a large literature in law and economics that stresses this argument. We adapt this reasoning to EU policy making, and analyze the interaction between the European Commission and member states in the presence of this uncertainty about judicial behavior.

We find that higher uncertainty with respect to the actual ECJ ruling increases non-compliance by the member state, irrespective of whether the European Commission, as the guardian of the treaty, will take member states to court. We also find that larger uncertainty about the preferences of the ECJ reduces the incidence by which the Commission takes a case to the ECJ. Furthermore, filing of cases to the ECJ occur if reputational costs of a member country's government are small relative to the reputational costs of the European Commission. Should the relative reputational costs be such that the ECJ is not asked for a decision, then policy deviation increases as reputational costs of the European Commission increase. For the other case where the European Commission seeks a decision of the ECJ, policy deviation increases as the reputational costs of the country which deviates are smaller.

In an extension we looked into interdependent decisions of member states to deviate from the directive. We find that the incidence of cases brought in front of the ECJ decreases. However, should a policy deviation be chosen that leads to an ECJ case, it is more deviant than without interdependent decisions of member states. Free-riding increases policy deviations, making it more likely that the ECJ rules in favor of the European Commission in the interdependent case. Knowing this, the alternative of avoiding an ECJ case becomes more attractive for each member country.

A possibility to take our predictions to the data might be the following. Related to the role of uncertainty in explaining non-compliance, we would conjecture that policy deviations should vary with the heterogeneity of preferences of a given number of judges deciding on these cases. Apart from the degree of uncertainty, we argue that potential costs from losing a case before the ECJ will influence the behavior of member states and the European Commission. Given that these costs are likely to differ between policy areas, an implication for testing could be that one should observe patterns of when such cases are brought to court and which party wins depending on relatively more or less important policy areas. However, these and other routes of empirical work go beyond the current insight we wanted to achieve, 
and, therefore, we leave it to future work.

\section{Appendix}

\section{Appendix A: The European Commission}

Given our assumption on the distribution of $\varepsilon$, the probability that the ECJ rules in favor of the Commission becomes $\operatorname{Prob}\left(\Delta_{i}>\varepsilon\right)=\frac{1}{2}+\frac{\Delta_{i}}{\mu}$. The European Commission would only go to court if the expected utility is higher than simply accepting the policy deviation by the member state. Formally, this requires

$$
\operatorname{Prob}\left(\Delta_{i}>\varepsilon\right) \cdot 0+\left(1-\operatorname{Prob}\left(\Delta_{i}>\varepsilon\right)\right)\left(-\Delta_{i}\left(1+\gamma_{C}\right)\right)>-\Delta_{i} .
$$

That is, if the ECJ rules in favor of the Commission, its losses are zero. If the ECJ rules against it, however, it has to bear the costs from the policy deviation and the associated loss of reputation. Using $\operatorname{Prob}\left(\Delta_{i}>\varepsilon\right)$ and rewriting gives (8) in the main text.

\section{Appendix B: The Single Country Case}

The expected utility from choosing to deviate for country $i$ is

$$
\begin{aligned}
E U_{i}\left(\Delta_{i}\right)= & \left.\operatorname{Prob}\left(\Delta_{i}>\varepsilon\right)\left[-\Delta_{i}^{*}-\Delta_{i} \gamma_{G}\right)\right] \\
& +\left(1-\operatorname{Prob}\left(\Delta_{i}>\varepsilon\right)\right)\left[-\left(\Delta_{i}^{*}-\Delta_{i}\right)\right],
\end{aligned}
$$

where the first part on the right hand side of the equation is the weighted payoff to country $i$ if the ECJ rules against it, and the second part constitutes the weighted payoff for the case of winning in front of the ECJ. Taking the first order condition and solving yields (9).

Then, country $i$ will choose policy $\widehat{\Delta}_{i}$ over the alternative of setting a deviation which is small enough to not trigger a lawsuit if the expected utility is higher than the utility from simply setting the critical level of deviation that will not trigger an involvement of the ECJ. Formally this is given as

$$
E U_{i}\left(\widehat{\Delta}_{i}\right)>-\left(\Delta_{i}^{*}-\bar{\Delta}_{i}\right)
$$

Inserting $E U_{i}, \widehat{\Delta}_{i}, \bar{\Delta}_{i}$ from eqs. (9), and (8), respectively, and rearranging yields (10). 


\section{Appendix C:}

For completeness, we show here the condition for $\widehat{\Delta}_{i}>\bar{\Delta}_{i}$ to hold. In this case, the expected utility for country $i$ from setting optimal policy and being sued yields a higher expected value than simply setting that value of deviation which is accepted by the Commission without involving the ECJ. Given the linearity of the utility function, this condition is equivalent to

$$
\frac{\mu}{4} \frac{1-\gamma_{G}}{1+\gamma_{G}}>\frac{\mu}{16} \frac{\left(1-\gamma_{G}\right)^{2}}{1+\gamma_{G}}>\mu\left(\frac{1}{2}-\frac{1}{1+\gamma_{C}}\right) .
$$

Notice that $\bar{\Delta}_{i}=\operatorname{Max}\left[0, \mu\left(\frac{1}{2}-\frac{1}{1+\gamma_{C}}\right)\right]$ so that the right hand side of this inequality is only positive if $\gamma_{C}>1$ whenever $\mu>0$, in all other cases the deviation accepted by the Commission would be zero, and the member state's decision would boil down to either setting $\Delta_{i}=0$ or accepting being brought to court. This, of course, only makes sense if $\widehat{\Delta}_{i}>0$ which requires that $1>\gamma_{G}$ from (9). If that is the case, $\frac{\mu}{4} \frac{1-\gamma_{G}}{1+\gamma_{G}}>\frac{\mu}{16} \frac{\left(1-\gamma_{G}\right)^{2}}{1+\gamma_{G}}$ is fulfilled as well. Our binding condition for having a court decision on the member states' behavior is thus $\gamma_{G}<1<\gamma_{C}$.

\section{Appendix D: The Many Countries Case}

Government $i$ 's expected utility is given by

$$
E U_{i}=\operatorname{Prob}\left(\frac{\sum \Delta_{i}}{n}>\varepsilon\right)\left(-\Delta_{i}^{*}-\gamma_{G} \Delta_{i}\right)+\left(1-\operatorname{Prob}\left(\frac{\sum \Delta_{i}}{n}>\varepsilon\right)\right)\left(-\Delta_{i}^{*}+\Delta_{i}\right)
$$

From $\frac{\partial E U_{i}}{\partial \Delta_{i}}=0$, country $i$ 's reaction function is $\Delta_{i}=-\frac{1}{2} \sum \Delta_{-i}+\frac{n \mu}{4} \frac{1-\gamma_{G}}{1+\gamma_{G}}$. Assuming full symmetry among countries, yields an equilibrium policy of (13) in the main text.

The final step is to see when a single country sets (13), knowing that this leads to a case before the ECJ, or when it prefers a deviation low enough that will not prompt the Commission to take it to court. Given symmetry, (12) becomes $\bar{\Delta}_{i}=\mu\left(\frac{1}{2}-\frac{1}{1+\gamma_{C}}\right)$. From $E U_{i}\left(\widehat{\Delta}_{i}\right)>-\left(\Delta_{i}^{*}-\bar{\Delta}_{i}\right)$, it follows that countries will set $\widehat{\Delta}_{i}$ instead of $\bar{\Delta}_{i}$ if (14) in the main text holds.

\section{Acknowledgements}

We would like to thank Stefania Baroncelli, Miriam Hartlapp, Achim Kemmerling, and Christian Martin for their suggestions, and Marco Ditz for his valuable research assistance. We have also profited from the comments given 
by the participants of the 6th Annual Conference on the Political Economy of International Organizations, in particular by our discussants Thomas Hale and Nikitas Konstantinidis.

\section{References}

BEBCHUK, L. A. (1984): "Litigation and settlement under imperfect information," The Rand Journal of Economics, 15, 404-415.

Burley, A.-M. AND W. MatTli (1993): "Europe before the court: a political theory of legal integration in the European Union," International Organization, 47, 41-76.

CARrubBA, C. J. (2005): "Courts and compliance in the international regulatory regimes," The Journal of Politics, 67, 669-689.

Carrubba, C. J., M. Gabel, and C. Hankla (2008): "Judicial behavior under political constraints: evidence from the European Court of Justice," American Political Science Review, 102, 435-452.

(2012): "Unterstanding the role of the European Court of Justice in European Integration," American Political Science Review, 106, 214-223.

Cooter, R. And D. Rubinfeld (1989): "Economic analysis of legal disputes and their resolution," Journal of Economic Literature, 27, 1067-1097.

Court of Justice of the European Union (2011): Annual Report 2010, Luxembourg, Publications Office of the European Union.

(2012): "Annual Report 2011, Synopsis of the work of the Court of Justice, the General Court and the Civil Service Tribunal," Tech. rep., Luxembourg: Publications Office of the European Union.

European Commission (2011): "Report from the Commission, 28th Annual Report on Monitoring the Application of EU Law (2010)," Brussels, 29.9.2011 COM(2011) 588 final.

Falkner, G., O. Treib, M. Hartlapp, and S. Leiber (2005): Complying with Europe. EU Minimum Harmonisation and Soft Law in the Member States, Cambridge: Cambridge University Press.

Garrett, G. (1992): "International cooperation and institutional choice: the European Community's internal market," International Organization, $46,553-560$. 
- (1995): "The politics of legal intergration in the European Union," International Organization, 49, 171-181.

Garrett, G., R. D. Kelemen, And H. Schulz (1998): "The European Court of Justice, national governments, and legal integration in the European Union," International Organization, 52, 149-176.

George, T. And L. Epstein (1992): "On the nature of Supreme Court decision making," American Political Science Review, 86, 323-337.

Hartlapp, M. And G. Falkner (2009): "Problems of operationalization and data in EU compliance research," European Union Politics, 10, 281304 .

Kelemen, D. (2012): "The political foundations of judicial independence in the European Union," Journal of European Public Policy, 19, 43-58.

KÖnig, T. And B. Luetgert (2008): "Troubles with transposition? Explaining trends in member-state notification and the delayed transposition of EU directives," British Journal of Political Science, 39, 163-194.

MALECKI, M. (2012): "Do ECJ judges all speak with the same voice?" Journal of European Public Policy, 19, 59-75.

Mattli, W. And A. Slaughter (1995): "Law and politics in the European Union: a reply to Garrett," International Organization, 49, 183-190.

Padovano, F., G. Sgarra, And N. Fiorino (2003): "Judicial branch, checks and balances and political accountability," Constitutional Political Economy, 14, 47-70.

Pollack, M. A. (2005): "Theorizing the European Union: international organization, domestic polity, or experiment in new governance," Annual Review of Political Science, 8, 357-398.

Posner, R. A. (1993): "What do judges and justices maximize? (The same thing as everybody else)," Supreme Court Economic Review, 3, 1-41.

Prechal, S. (1995): Directives in the European Community Law, A Study of Directives and Their Enforcement in National Courts, Oxford, Clarendon Press.

Segal, J. And H. Spaeth (1996): "The influence of stare decisis on the vote of the United States Supreme Court justices," American Journal of Political Science, 40, 971-1003. 
Shepsle, K. A. And M. S. Bonchek (1997): Analyzing Politics - Rationality, Behavior, and Institutions, New York: Norton.

Songer, D. And S. Lindquist (1996): "Not the whole story: The impact of justices' values on Supreme Court decision making," American Journal of Political Science, 40, 1049-1063.

SteunenberG, B. (2010): "Is big brother watching? Commission oversight of the national implementation of EU directives," European Union Politics, $11,359-380$.

SteunenberG, B. And W. Voermans (2006): "The transposition of EC directives: a comparative study of instruments, techniques and processes in six member states," Tech. rep., Report for the Dutch Ministry of Justice, Leiden University.

Stone Sweet, A. And T. Brunell (2012): "The European Court of Justice, state noncompliance, and the politics of override," American Political Science Review, 106, 204-213.

Treutlein, D. (2009): "Zooming in on transposition: national execution measures for EU directives 1986-2002," CESifo Economic Studies, 55, 94109.

Voigt, S. (2011): "Positive constitutional economics II - a survey of recent developments," Public Choice, 146, 205-256. 